\title{
PENINGKATAN PENGETAHUAN, KETERAMPILAN DAN SIKAP PARA KAUM MUDA DALAM PERSIAPAN MEMASUKI DUNIA KERJA
}

\author{
Linus Kali Palindangan ${ }^{1}$
}

\author{
${ }^{1}$ Program Studi Ilmu Komunikasi, Sekolah Tinggi Ilmu Komunikasi dan Sekretari Tarakanita Jakarta \\ Email: kalipalindanganlinus@gmail.com
}

\begin{abstract}
This training activity was held thanks to the collaboration of the Tarakanita School of Communication Science and Secretariat (STIKS Tarakanita) Jakarta with the Jakarta Marga Sejahtera Non-Governmental Organization. This activity was held to provide knowledge and training for young people from Marga Sejahtera NGOs. The youths from the NGO Marga Sejahtera are all high school and vocational high school graduates who have not yet found work. All of them are then gathered to be given various knowledge, skills and attitudes which are expected to facilitate and assist them in finding work and work. The method used in this activity is training. While the speakers of this training are Tarakanita STIKS lecturers. There are also results obtained from this training are (1) participants have adequate knowledge about the world of work, (2) participants are skilled in preparing a letter of application and CV, (3) participants are skilled in accessing information on job opportunities through various media including procedures for applying for jobs in a way online, (4) participants send applications to companies that open job vacancies according to participant specifications, and (5) participants have good attitude and personal performance. Based on the evaluation of the participants both verbally and in writing at the end of the event, it was concluded that a similar activity was highly recommended for job seekers, both high school / vocational and graduate graduates. Because this activity is considered very helpful for each participant in preparing to get a job.
\end{abstract}

Keywords: Knowledge; Skills; attitude; working life

\begin{abstract}
ABSTRAK
Kegiatan pelaltihan ini terselenggara berkat kerjasama Sekolah Tinggi Ilmu Komunikasi dan Sekretari Tarakanita (STIKS Tarakanita) Jakarta dengan Lembaga Swadaya Masyarakat Marga Sejahtera Jakarta. Kegiatan ini diselenggarakan untuk memberika pengetahuan dan latihan bagi para pemuda dari LSM Marga Sejahtera. Para pemuda dari LSM Marga Sejahtera semuanya adalah lulusan SMU dan SMK yang belum mendapatkan pekerjaan. Mereka semua kemudian dikumpulkan untuk selanjutnya diberikan berbagai pengetahuan, keterampilan dan sikap yang diharapkan akan memudahkan dan membantu mereka dalam mencari pekerjaan dan bekerja. Metode yang dipakai dalam kegiatan ini adalah pelatihan. Sementara para narasumber pelatihan ini adalah para dosen STIKS Tarakanita. Ada pun hasil yang diperoleh dari pelatihan ini adalah (1) perserta mempunyai pengetahuan yang memadai tentang dunia kerja, (2) peserta terampil menyusun surat lamaran dan CV, (3) peserta terampil mengakses informasi peluang kerja melalui berbagai media termasuk tata cara melamar pekerjaan secara online, (4) peserta mengirim lamaran ke perusahaan yang membuka lowongan pekerjaan sesuai spesifikasi peserta, dan (5) peserta memiliki sikap dan personal performance baik. Berdasarkan evaluasi dari peserta baik secara lisan maupun tertulis diakhir acara, disimpulkan bahwa kegiatan yang serupa sangat direkomendasikan bagi para pencari kerja, baik lulusan SMU/SMK maupun lulusan sarjana. Kegiatan ini dipandang sangat membantu setiap peserta dalam mempersiapkan diri mendapatkan pekerjaan.
\end{abstract}

Kata kunci: Pengetahuan; keterampilan; sikap; dunia kerja.

\section{PENDAHULUAN}

Sudah tidak diragukan lagi, bahwa saat ini persaingan memasuki dunia kerja semakin ketat, sementara para calon tenaga kerja justru masih banyak diliputi oleh permasalahan; mulai dari permasalahan yang sederhana hingga permasalahan yang berat dan rumit. Ketidakmampuan menyusun surat lamaran sesuai format surat yang resmi, keterbatasan dalam mengakses informasi dan peluang kerja, keterbatasan pemahaman akan pentingnya penampilan sebagai faktor penunjang, serta berbagai hal teknis menyangkut komunikasi adalah merupakan beberapa bentuk konkret permasalahan yang ada. Belum lagi faktor-faktor di luar para calon tenaga kerja seperti 
tingginya kompetisi dalam dunia kerja, sistem ketenagakerjaan yang belum berpihak pada para calon pekerja dan sebagainya. Semua permasalahan tersebut menuntut penyelesaian yang nyata.

Sebagai sebuah lembaga pendidikan di Jakarta, STIKS Tarakanita terpanggil untuk ikut bertanggung jawab dalam upaya mencerdaskan kehidupan bangsa. Kesadaran akan tanggung jawab tersebut selanjutnya terwujud dalam berbagai kegiatan pengabdian kepada masyarakat yang ditangani oleh unit Pengabdian pada Masyarakat (PpM) STIKS Tarakanita. Salah satu bentuk kegiatan tersebut adalah Pelatihan Peningkatan Pengetahuan, Keterampilan, dan Sikap Para Kaum Muda dalam persiapan memasuki dunia kerja. Kegiatan ini merupakan wujud kerjasama antara STIKS Tarakanita dalam hal unit PpM dengan Lembaga Swadaya Masyarakat (LSM) Marga Sejahtera.

Marga Sejahtera merupakan salah satu lembaga swadaya masyarakat yang peduli terhadap hakhak anak. Lembaga ini bekerja untuk anak-anak yang mengalami penelantaran, pengucilan, dan kerentanan. Lembaga ini didirikan pada 17 Desember 1979 di Jakarta dan bekerja sama dengan Child Fun Indonesia melalui sistem Sponsorship. Sejak berdirinya hingga saat kini, lembaga ini telah berhasil mendampingi lebih 10.000 anak berusia antara 2-22 tahun di beberapa wilayah di DKI Jakarta. Saat ini Marga Sejahtera sedang melakukan pendampingan anak di empat kelurahan di DKI Jakarta. Keempat wilayah itu adalah: Pasar Minggu Jakarta Selatan, Menteng Dalam Jakarta Selatan, Kelurahan Pulo Gadung Jakarta Timur dan Jati Padang. Ada pun jumlah anak yang didampingi di empat wilayah tersebut saat ini adalah 1.073 anak.

Salah satu fokus utama Marga Sejahtera dalam mendampingi kaum muda saat ini adalah mendapingi mereka untuk mendapatkan pekerjaan yang layak dan bermartabat. Usaha ini sejalan dengan Visi dan Misi Marga Sejahtera: yakni mewujudkan anak Indonesia yang andal dan berkualitas, berwawasan ke depan, menuju suatu masyarakat yang sejahtera dan mandiri. Ada pun misinya adalah meningkatkan kualitas dan kesejahteraan anak Indonesia melalui upaya-upaya peningkatan kesadaran, pengetahuan dan kemampuan masyarakat, untuk mengembangkan potensi anak sesuai dengan hak-haknya serta penciptaan lingkungan yang memberi peluang, dukungan, kebebasan dan perlindungan untuk menunjang perkembangan rohani, jasmani, mental dan sosial.

Sebagai sebuah lembaga swadaya masyarakat, Marga Sejahtera hendak menjalankan fungsi dan peranannya untuk: (1) membantu dan memfasilitasi anak-anak yang mengalami permasalahan dan hambatan dalam pemenuhan hak-hak dasarnya; (2) mengembangkan peran dan partisipasi anakanak agar mampu mempersiapkan diri sebagai generasi muda yang mandiri dan kompeten; (3) membantu Pemerintah dalam bidang pendampingan dan perlindungan anak-anak, dan (4) menyelenggarakan kegiatan advokasi hak-hak anak.

Dalam rangka mewujudkan fungsi dan perannya tersebut, Marga Sejahtera melakukan evaluasi terhadap anak-anak dampingan mereka. Berdasarkan hasil evaluasi tersebut diketahui bahwa ternyata sebagian besar anak-anak dampingan tersebut sebenarnya telah lulus sekolah SMU/SMK. Namun mereka ternyata sulit mencari dan menemukan pekerjaan yang layak. Kalau pun mereka mendapatkan pekerjaan, kondisi tempat kerja mereka umumnya tidak memenuhi standar kerja dengan upah yang berada di bawah standar upah minimum. Berdasarkan hasil observasi sementara diketahui bahwa situasi tersebut sesungguhnya tidak lepas dari beberapa faktor seperti: (1) kurang percaya diri dalam menghadapi orang lain; (2) banyak anak yang belum mengetahui bagaimana cara melamar kerja secara langsung maupun secara Online; (3) bahkan hampir semuanya belum tahu bagaimana cara menghadapi dan menjawab pertanyaan-pertanyaan yang sering diajukan dalam wawancara kerja. 
Berangkat dari situasi demikian maka Marga Sejahtera kemudian mengusulkan kepada STIKS Tarakanita dalam hal ini unit PpM STIKS Tarakanita untuk saling bekerjasama memberikan pelatihan kepada anak-anak dampingannya Marga Sejahtera tersebut. Para peserta pelatihan ini yang semuanya berjumlah 76 orang, merupakan anak muda lulusan Sekolah Menengah Umum dan Sekolah Menengah Kejuruan, berdomisili di Jakarta dan sekitarnya, belum bekerja dan didampingi oleh Marga Sejahtera.

\section{TARGET DAN LUARAN}

Materi pelatihan ini dikemas dalam tiga sesi. Sesi pertama, peserta diarahkan untuk mengenali diri dan peluang kerja. Pada sesi ini peserta diajak untuk mengenal situasi konkrit yang dihadapi, kekuatan dan kelemahan mereka dimiliki, dan peluang yang mungkin dapat diperoleh masingmasing peserta. Selain itu peserta juga dibekali dengan pengetahuan tentang etika-etiket dan penampilan diri yang penting dalam melamar kerja.

Sesi kedua, peserta dibimbing dan dilatih untuk menulis Curriculum Vitae $(C V)$ dan Surat Lamaran Kerja baik dalam Bahasa Indonesia maupun dalam Bahasa Inggris. Pada sesi ini para peserta dilatih menulis $\mathrm{CV}$ dan surat lamaran kerja serta menyiapkan dokumen lain yang dibutuhkan dalam 2 (dua) versi, yaitu versi Bahasa Indonesia dan versi Bahasa Inggris. Sesi ketiga, peserta diajari dan dilatih strategi menghadapi psikotest dan wawancara kerja. Pada sesi ini para peserta akan dikenalkan ajari dan dilatih untuk mengerjakan berbagai jenis psikotest dengan berbagai tujuan dan cara mengerjakannya yang umumnya dipakai dalam proses rekrutmen tenaga kerja. Mereka diajari pula tentang bagaimana cara menghadapi wawancara kerja, daftar pertanyaan yang mungkin diajukan dalam wawancara kerja, baik dalam bahasa Indonesia maupun dalam bahasa Inggris. Peserta akan dilatih serta diberikan tips and trick atau kiat-kiat cara menjawab pertanyaanpertanyaan sebelum mereka mempraktekkannya sendiri dalam bentuk role play.

Setelah mengikuti pelatihan ini, para peserta diharapkan minimal (1) memiliki pengetahuan yang memadai tentang dunia kerja, (2) terampil menyusuun lamaran dan Curiculum Vitae, (3) terampil mengakses informasi peluang kerja melalui berbagai media termasuk tata cara melamar pekerjaan secara online, (4) mengirim lamaran ke perusahaan yang membuka lowongan pekerjaan sesuai spesifikasi peserta, dan (5) memiliki sikap dan personal performance baik. Misalnya dalam mengikuti wawancara peserta lebih percaya diri dan mampu menjawab pertanyaan-pertanyaan yang diajukan dengan harapan bahwa jawaban-jawaban akan berkenan dan menarik pewawancara dan akhirnya memenangkan peluang kerja.

\section{METODE PELAKSANAAN PKM}

Kegiatan ini laksanakan dalam bentuk pelatihan (lihat Tabel 1). Beberapa materi seperti etiket dan penampilan profesional dan mengikuti wawancara disampaikan dalam bentuk ceramah oleh para narasumber. Sementara itu para peserta mendengar, mencatat yang perlu, bertanya atau memberikan tanggapan. Sementara materi pelatihan seperti, menulis surat lamaran dan cv, baik dalam Bahasa Indonesia maupun Bahasa Inggris, Psiko test, dan melamar pekerja secara online dilaksanakan melalui praktik langsung di komputer, sementara itu para narasumber menunjukkan contoh, mengarahkan dan mendampingi para peserta. Khusus untuk wawancara dilakukan pula dalam bentuk role play di ruangan tersendiri. Ruangan tersebut dikondisikan menyerupai ruang untuk wawancara di mana tiga orang narasumber selaku pewawancara telah siap. Sementara itu setiap peserta begiliran seorang demi seorang memasuki ruangan tersebut dan diwawancara disaksikan oleh para peserta lain melalui video conference. Melalui kegiatan ini semua peserta 
terdorong untuk berproses secara aktif, bertanya, menjawab, serta saling memberikan komentar dan saran satu sama lain.

Tabel 1. Susunan Acara Pelatihan

\section{HARI I}

\begin{tabular}{|c|c|c|c|c|}
\hline $\mathrm{NO}$ & JAM & ACARA & PEMBICARA & RUANGAN \\
\hline 1 & $\begin{array}{l}08.00- \\
08.15\end{array}$ & Registrasi & & $\begin{array}{l}\text { Gedung } \\
\text { Carlo }\end{array}$ \\
\hline 2 & $\begin{array}{l}08.15- \\
08.30\end{array}$ & Pembukaan dan Sambutan & $\begin{array}{l}\text { 1. Sambutan Selamat Datang } \\
\text { oleh MC.Bpk. Linus K. } \\
\text { 2. Menyanyikan Lagu } \\
\text { Indonesia Raya.-Marga } \\
\text { Sejahtera } \\
\text { 3.Doa-Marga Sejahtera } \\
\text { 4.Sambutan Project Director } \\
\text { Marga Sejahtera- Ibu Liest } \\
\text { Paranowo } \\
\text { 5. Sambutan Donor-Marga } \\
\text { Sejahtera } \\
\text { 6.Sambutan dan Pembukan } \\
\text { oleh Ketua STIKS } \\
\text { Tarakanita/Waket I Kepala } \\
\text { LPPM } \\
\text { 7. Simbolisasi Penyerahan } \\
\text { MoU-Margasejahtera-STIKS } \\
\text { Tarakanita }\end{array}$ & $\begin{array}{l}\text { Gedung } \\
\text { Carlo }\end{array}$ \\
\hline 3 & $\begin{array}{l}08.30- \\
10.00\end{array}$ & $\begin{array}{l}\text { Menulis Surat Lamaran dan } \\
\text { Daftar Riwayat Hidup dalam } \\
\text { bahasa Indonesia }\end{array}$ & $\begin{array}{l}\text { Jati Wahyono Agustinus, } \\
\text { M.Pd. (Kls 112) mhswa } 1 \\
\text { Maria Estri Wahyuningsih, } \\
\text { M.Pd.(Kls 113) mhswa } 1\end{array}$ & $\begin{array}{l}\text { Ruang } \\
112,113\end{array}$ \\
\hline 4 & 10.00 & Kudapan & Perkumpulan Marga Sejahtera & Ruang 115 \\
\hline 5 & $\begin{array}{l}10.15- \\
11.45\end{array}$ & $\begin{array}{l}\text { How to Write Letter and } C V \\
\text { effectively? }\end{array}$ & $\begin{array}{l}\text { Yulita Daru Priliantari } \\
\text { Maria F.Lies } \\
\text { Wisnu Wirawan } \\
\text { Mahasiswa } 2\end{array}$ & 112,113 \\
\hline 6 & $\begin{array}{l}12.00- \\
13.00\end{array}$ & Makan Siang & Perkumpulan Marga Sejahtera & Ruang 115 \\
\hline 7 & $\begin{array}{l}13.00- \\
14.30\end{array}$ & $\begin{array}{l}\text { Etiket dan Penampilan } \\
\text { Profesional }\end{array}$ & $\begin{array}{l}\text { Istudiyanti Priatmi } \\
\text { Elsie Oktivera } \\
\text { Bertha Reni } \\
\text { Mahasiswa } 2\end{array}$ & 112,113 \\
\hline 8 & $\begin{array}{l}14.30- \\
16.00\end{array}$ & $\begin{array}{l}\text { Praktik Psikologi Industri } \\
\text { dalam menyeleksi karyawan } \\
\text { berdasarkan latar belakang, } \\
\text { minat \& bakat, IQ, EQ \& SQ. } \\
\text { - Sharing }\end{array}$ & $\begin{array}{l}\text { Linus Kali Palindangan } \\
\text { Yohanes Jhony Kurniawan } \\
\text { Hydriana Ananta Win } \\
\text { Mahasiswa } 2\end{array}$ & \\
\hline
\end{tabular}


Tabel 1. Susunan Acara Pelatihan (lanjutan)

Hari II

\begin{tabular}{|c|c|c|c|c|}
\hline $\mathrm{NO}$ & JAM & ACARA & PEMBICARA & RUANGAN \\
\hline 1 & $\begin{array}{l}08.00- \\
08.15\end{array}$ & Registrasi & & Selasar lab \\
\hline 2 & $\begin{array}{l}08.15- \\
10.15\end{array}$ & $\begin{array}{l}\text { Melamar pekerjaan } \\
\text { berbasis On-Line } \\
\text { System }\end{array}$ & $\begin{array}{l}\text { Petrus Dwi Ananto, M.Msi. (lab A) } \\
\text { Yoseph Hendrik Maturbongs } \\
\text { Matilda Ujulawa, S.Kom } \\
\text { mahasiwa } 2\end{array}$ & Lab. Komputer \\
\hline 3 & 10.15 & Kudapan & Perkumpulan Marga Sejahtera & Selasa \\
\hline 4 & $\begin{array}{l}10.30- \\
12.00\end{array}$ & $\begin{array}{l}\text { Teknik Wawancara } \\
\text { yang efektif - } \\
\text { Simulasi }\end{array}$ & $\begin{array}{l}\text { Koesmaryanto Oetomo } \\
\text { Tommy Freibert Laluyan } \\
\text { Elsie Oktivera }\end{array}$ & $\begin{array}{c}\text { Lab. } \\
\text { Kesekretarisan }\end{array}$ \\
\hline 5 & $\begin{array}{l}12.00- \\
13.00\end{array}$ & Makan Siang & Perkumpulan Marga Asih & Ruang 112 \\
\hline 6 & $\begin{array}{l}13.00- \\
14.30\end{array}$ & $\begin{array}{l}\text { How to handle } \\
\text { interview effectively? }\end{array}$ & $\begin{array}{l}\text { Yakobus Suharyono } \\
\text { Taripar Siregar } \\
\text { C. Widi Astuti }\end{array}$ & $\begin{array}{c}\text { Lab. } \\
\text { Kesekretarisan }\end{array}$ \\
\hline 7 & $\begin{array}{l}14.30- \\
16.30\end{array}$ & $\begin{array}{l}\text { Praktik Role play } \\
\text { wawancara }\end{array}$ & $\begin{array}{l}\text { Para pembicara selama pelatihan } \\
\text { (hari Sabtu dan Minggu) }\end{array}$ & $\begin{array}{c}\text { Lab. } \\
\text { Kesekretarisan }\end{array}$ \\
\hline & $\begin{array}{l}16.30- \\
17.00\end{array}$ & $\begin{array}{l}\text { Kesan dan pesan dari } \\
\text { peserta } \\
\text { Penutup dan pesan- } \\
\text { pesan }\end{array}$ & $\begin{array}{l}\text { Perwakilan peserta } \\
\text { 1.Project Director Marga Sejahtera } \\
\text { 2. Puket I / Kepala P3M } \\
\text { 3. Doa Penutup dan Menyanyikan } \\
\text { Lagu Nasional oleh Marga } \\
\text { Sejahtera }\end{array}$ & $\begin{array}{c}\text { Lab. } \\
\text { Kesekretarisan }\end{array}$ \\
\hline
\end{tabular}

\section{HASIL DAN PEMBAHASAN}

Para peserta pelatihan yang semuanya berasal dari keluarga kurang mampu, rentan terabaikan hakhaknya. Baik itu hak mereka sebagai anak di dalam keluarga, hak mereka sebagai warga masyarakat, hak mereka sebagai warga negara maupun dan terutama hak mereka sebagai manusia. Bagaimana pun mereka sesungguhnya adalah kelompok yang belum sepenuhnya sadar akan hak mereka. Justru karena itu mereka belum sadar untuk berusaha mendapatkan hak-hak tersebut. Karena belum sadar akan hak-haknya maka perlu suatu kegiatan bagi mereka ini agar hak-hak mereka terlindungi. (Abdi Koro, 2010) Melalui Lembaga Marga Sejahtera, mereka dampingin dan diarahkan agar mereka sedikit demi sedikit menyadari hak-hak mereka dan selanjutnya memperjuangkannya.

Kegiatan pelatihan ini adalah salah satu upaya membekali para peserta dengan pengetahuan, keterampilan dan sikap agar hak mereka sebagai manusia dapat memdapatkan pekerjaan yang layak. Sebab pengetahuan, keterampilan dan sikap yang sudah dilatih dapat diaplikasikan dan dapat memberikan pengaruh, sehingga memungkinkan anak mampu bersaing dan memperoleh pekerjaan atau bahkan mampu menciptakan pekerjaan dengan berwirausaha (Murhadi \& Karnawati; 2017) Untuk tujuan itulah maka pelatihan ini dirancang sedemikian rupa sehingga para peserta mampu berjuang untuk mendapatkan pekerjaan. Tidak heran apabila para peserta pelatihan ini diminta pula untuk membawa semua dokumen pribadi yang dibutuhkan untuk melamar pekerjaan. Dokumen-dokumen tersebut discan dan diserahkan ke para peserta untuk selanjutnya dikirimkan bersama dengan lamaran dan cv yang telah mereka buat sebelumnya. Karena itu 
mereka langsung diajari untuk menemukan lowongan pekerjaan secara online dan didampingi untuk mengirim lamaran mereka ke perusahaan-perusahaan yang membuka lowongan tersebut.

Berdasarkan hasil evaluasi yang disampaikan oleh para peserta baik secara lisan diakhir acara maupun secara tertulis yang dibagikan kepada setiap peserta, diketahui bahwa kegiatan pelatihan ini sangat bermanfaat bagi mereka (Tabel 2). Mereka mengaku senang mengikuti pelatihan ini, karena mereka belajar untuk menulis surat lamaran sesuai seharusnya, dalam bahasa Inggris maupun bahasa Indonesia. Tidak hanya itu mereka juga mengaku tahu cara mengerjakan psikotest melalui pelatihan ini. Bahkan cara bersikap, berbicara dan menjawab pertanyaan bukan hanya dipelajari tetapi sungguh-sungguh dipraktekkan dalam pelatihan ini. Yang terakhir dan yang terpenting kata mereka adalah mereka dapat mengirim lamaran mereka secara online dalam pelatihan ini.

Berikut ini kami sampaikan gambaran hasil evaluasi implementasi materi yang disampaikan oleh para peserta dalam pelatihan ini. Hasil evaluasi kegiatan pelatihan ini memberikan gambaran bahwa para peserta seluruhnya menyadari manfaat dari pelatihan ini. Bahkan lebih dari $71 \%$ peserta menyadari bahwa pelatihan ini sangat berguna bagi mereka dalam mencari pekerjaan.

Tabel 2. Evaluasi Implementasi Materi

\begin{tabular}{|l|c|c|c|c|}
\hline \multicolumn{1}{|c|}{ Implementasi materi } & $\begin{array}{c}\text { Tidak } \\
\text { berguna }\end{array}$ & $\begin{array}{c}\text { Cukup } \\
\text { berguna }\end{array}$ & berguna & $\begin{array}{c}\text { Sangat } \\
\text { berguna }\end{array}$ \\
\hline Materi bermanfaat bagi peserta & $0 \%$ & $4 \%$ & $44 \%$ & $52 \%$ \\
\hline $\begin{array}{l}\text { Materi bermanfaat dalam } \\
\text { mencari pekerjaan }\end{array}$ & $0 \%$ & $2 \%$ & $26 \%$ & $71 \%$ \\
\hline Materi bermanfaat dalam bekerja & $0 \%$ & $12 \%$ & $47 \%$ & $37 \%$ \\
\hline $\begin{array}{l}\text { Penerapan } \\
\text { pengetahuan/keterampilan/sikap }\end{array}$ & $0 \%$ & $8 \%$ & $50 \%$ & $41 \%$ \\
\hline
\end{tabular}

Sementara evaluasi terhadap kemampuan narasumber menunjukkan bahwa secara umum para peserta mengatakan para narasumber menguasai materi, mampu menyampaikan materi dengan baik dan terampil dalam menggunakan media dalam memberikan pelatihan ini. Meskipun demikian terdapat $2 \%$ peserta yang mengatakan bahwa para narasumber tidak menguasai materi dan $4 \%$ peserta mengatakan narasumber tidak menguasai penggunaaan media dalam memberikan pelatihan ini. Untuk lebih lengkapnya gambaran hasil evaluasi kemampuan narasumber kami tampilkan dalam Tabel 3.

Tabel 3. Evaluasi Kemampuan Narasumber

\begin{tabular}{|c|c|c|c|c|}
\hline Kemampuan Narasumber & $\begin{array}{c}\text { Tidak } \\
\text { menguasai }\end{array}$ & $\begin{array}{c}\text { Cukup } \\
\text { menguasai }\end{array}$ & menguasai & $\begin{array}{c}\text { Sangat } \\
\text { menguasai }\end{array}$ \\
\hline Penguasaan terhadap materi & $2 \%$ & $8 \%$ & $53 \%$ & $31 \%$ \\
\hline Penguasaan pemakaian media & $4 \%$ & $6 \%$ & $47 \%$ & $43 \%$ \\
\hline Penguasaan metode penyajian & $0 \%$ & $5 \%$ & $56 \%$ & $37 \%$ \\
\hline
\end{tabular}

Terdapat pula saran tertulis yang diberikan oleh sebagian peserta berkaitan dengan narasumber. Adapun saran tertulis tersebut dapat kami ringkas dalam beberapa butir berikut ini: (1) perlu memilih narasumber yang sungguh-sungguh kompeten sesuai dengan bidang ilmunya; (2) metode 
penyampaikan materi perlu lebih interaktif; (3) narasumber perlu lebih aktif berinteraksi dengan peserta.

Rupanya pelatihan ini meninggalkan beberapa kesan yang baik bagi para peserta seperti yang mereka tuliskan ini: (1) materi, praktik dan latihan yang diberikan dalam pelatihan dinilai sangat berguna oleh para peserta sebagai persiapan memasuki dunia kerja; (2) praktik-praktik yang dilakukan dengan fasilitas yang sangat mendukung, disadari para peserta akan sangat mambantu mereka dalam mempersiapkan diri memasuki dunia kerja yang sesungguhnya; (3) para peserta menyadari bahwa pelatihan ini berlangsung secara tertib, aman, dan menyenangkan bahkan ada beberapa yang mengaku berminat untuk ikut kembali jika ada kegiatan yang serupa. Oleh karena itu pelatihan seperti ini sangat direkomendasikan bagi para pencari kerja, baik lulusan SMU/SMK maupun lulusan sarjana. Sebab kegiatan kegiatan pelatihan ini dipandang sangat membantu setiap peserta dalam mempersiapkan diri mendapatkan pekerjaan.

\section{KESIMPULAN DAN SARAN}

Kegiatan pelatihan ini terselenggara berkat kerjasama antara STIKS Tarakanita dengan Marga Sejahtera. Tujuannya adalah meningkatkan pengetahuan, keterampilan, dan sikap para anak muda dari Marga Sejahtera agar mereka lebih mampu mempersiapkan diri mereka dalam memasuki dunia kerja. Setelah mengikuti pelatihan ini para peserta sudah (1) mempunyai pengetahuan yang memadai tentang dunia kerja, (2) terampil menyusun lamaran dan CV, (3) terampil mengakses informasi peluang kerja melalui berbagai media termasuk tata cara melamar pekerjaan secara online, (4) mengirim lamaran ke perusahaan yang membuka lowongan pekerjaan sesuai spesifikasi peserta, dan (5) memiliki sikap dan personal performance baik dalam wawancara.

Berdasarkan evaluasi dari peserta baik secara lisan maupun tertulis diakhir acara, disimpulkan bahwa kegiatan yang serupa sangat direkomendasikan bagi para pencari kerja, baik lulusan SMU/SMK maupun lulusan sarjana. Kegiatan ini dipandang sangat membantu setiap peserta dalam mempersiapkan diri mendapatkan pekerjaan. Agar pelatihan serupa di masa datang dapat lebih berhasil, maka disarankan supaya: (1) para narasumber yang dipilih sungguh-sungguh kompeten sesuai dengan bidang ilmunya; (2) metode penyampaikan materi lebih interaktif; (3) narasumber lebih aktif berinteraksi dengan peserta.

\section{Ucapan Terima Kasih}

Kegiatan pelatihan ini terselenggara berkat dukungan dari berbagai pihak. Oleh sebab itu perkenankanlah kami menyampaikan terima kasih kepada: Pimpinan STIKS Tarakanita yang telah mendukung tersenggaranya acara ini. Baik dukungan dana, fasilitas maupun tenaga. Kepada Lembaga Marga Sejahtera yang telah mengantar dan mendampingi para anak muda untuk datang mengikuti Pelatihan Peningkatan Pengetahuan, Keterampilan, dan Sikap Para Kaum Muda dalam persiapan memasuki dunia kerja di Kampus STIKS Tarakanita Jakarta. Tidak lupa pula ucapan terima kasih kepada para dosen STIKS Tarakanita selaku narasumber pelatihan ini, para karyawan dan mahasiswa yang sudah terlibat membantu terselenggaranya kegiatan ini sesuai dengan tugas mereka masing-masing.

\section{REFERENSI}

Abdi Koro, H.M. 2010. Perlindungan Hukum Terhadap Anak di bawah Umur dalam Upaya Mengembangkan Kualitas Sumber Daya Manusia. Jurnal Wacana, Vol. IX, No. 29 Mei 2010. Hlm. 123-136.

Abin, Syamsuddin. 2003. Psikologi Pendidikan. PT Remaja Rosda Karya, Bandung 
Amandemen IV. Undang-Undang Nomor 39 Tahun 1999. Tentang Hak Asasi Manusia. AlHikmah. 2002, Surakarta.

Ginting, Selamat. 2011. Berdayakan Anak. Republika. Jakarta. 31 Mei. Diunduh dari (http://republikaonline.com) pada 30 Juli 2019

Herlina, Apong dkk. 2003. Perlindungan Anak Berdasarkan Undang-Undang No. 23 Tahun 2002 Tentang Perlindungan Anak. Harapan Prima, Jakarta

Murhadi dan Karnawati, R.A. 2017. Dampak Model Pelatihan Keterampilan Dalam Meningkatkan Kompetensi Anak Jalanan untuk Memperoleh Pekerjaan di Tengerang Selatan. Jurnal Ilmiah Widya, Vol. 4. No. 2 Agustus-Desember 2017. 